Preprints of the

Max Planck Institute for

Research on Collective Goods

Bonn 2009/1

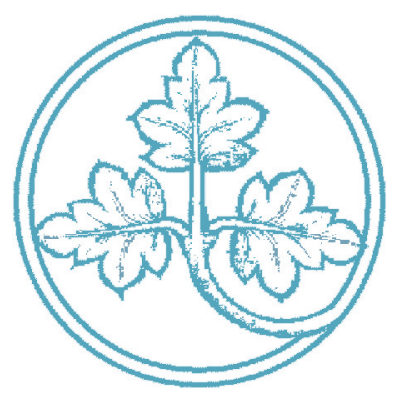

Environmental dilemmas

revisited: structural

consequences from the

angle of institutional

ergonomics

Martin Beckenkamp

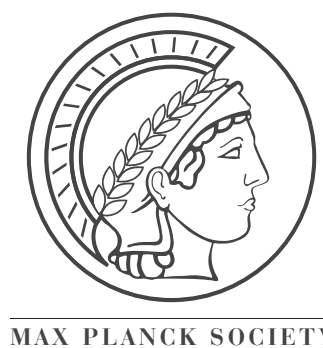




\title{
Environmental dilemmas revisited: structural consequences from the angle of institutional ergonomics
}

\author{
Martin Beckenkamp
}

January 2009 


\title{
Environmental dilemmas revisited: structural consequences from the angle of institutional ergonomics
}

\author{
Martin Beckenkamp*
}

\begin{abstract}
The structure of a social dilemma lies behind many environmental problems. Mingling temporal aspects of resources with the structure of the social dilemma often leads to wrong conclusions. Therefore, it is worth analytically separating temporal aspects from structural aspects of the dilemma. This article concentrates solely on the structural aspects of the dilemma and the grades of complexity with respect to the number and stakes of the people involved, as well as the asymmetry of endowments and the salience of the optimal use of the resource in order to come close to the welfare optimum. Dilemmas with sufficient complexity are extremely vulnerable to individual defectors, and therefore institutions are necessary for the solution of the dilemma. Consequently, research in environmental psychology should not only target the individuals, but focus on institutional design with respect to (1) the structural diagnosis of environmental dilemmas; (2) methods that provide an insight into the structural problem of environmental dilemmas; (3) the impact of institutions on internalizing norms; and (4) the impact of structural knowledge about the dilemma of accepting institutions that help to solve the environmental dilemma. In analogy to software-ergonomics, psychology should initiate research in institutional ergonomics that helps to create addressee-friendly institutions.
\end{abstract}

Keywords: Social dilemma, Resource dilemma, Game theory, environment, institutional design.

Address Correspondence to: Privatdozent Dr. Martin Beckenkamp, MPI for the Research on Collective Goods, Kurt-Schumacher-Straße 10, 53115 Bonn, Germany 


\section{The social dilemma in environmental problems and the imperative of institutions}

We are drastically endangering nature and species. Almost every nature museum demonstrates to us the increasing destruction of nature. Nowadays, many people are aware of this background and the threat. Nevertheless, the destruction of biodiversity continues. When homo sapiens knows about his role in wreaking havoc, why does he continue such behavior? Does the moralizing finger prevent these harmful consequences? Should we shame car drivers, fishermen and air passengers? This does not help much, if the addressees are in a social dilemma, a situation where the reason benefiting the community is in contrast to the individual rationality of a homo oeconomicus.

Beyond many environmental problems, there is the structure of a social dilemma. Since Hardin (cf. 1968), environmental social dilemmas are tagged as "the tragedy of the commons", and it is well known in environmental psychology that many environmental problems are social dilemmas: "The-tragedy-of-the-commons process underlies most problems of environmental pollution, just as it underlies the depletion of most natural resources" (Gardner \& Stern, 1996, p. 25).

However, and this is the first central issue of my article, many of the current approaches that aim at changing the individuals' values, attitudes or norms are inadequate for the solution of the dilemma. Complex dilemmas need institutional solutions, and institutional solutions need the acceptance of their addressees. The addressees' acceptance of institutions crucially depends on the insight into the problem the institution is designed to solve. Therefore, and this is the second central issue of my article, addressees should know that they are involved in a social dilemma. Transparency about the dilemma can make it clear to individuals why a specific institutional change is necessary, and why a corresponding institution exists. Gardner and Stern (1996) allude to the fact that the people involved in a social dilemma and in causing destruction are mostly innocent, because "each is powerless to stop the process via unilateral individual action" (p. 26). This insight is important, because it implies that solutions targeting behavioral change in individual addressees - like changing attitudes - may fail due to the lack of power in individual action, and hence institutional design is necessary. However, institutional design itself may be efficient and inefficient, and part of the efficiency or inefficiency of institutions can be explained by psychology. This leads to the third issue of my article, i.e., that psychology should participate in the interdisciplinary research on institutional design, and enrich current approaches in institutional design, like for instance Epstein's “simple rules for a complex world” (1997) with psychological knowledge.

It seems obvious that psychological research could contribute with a rich knowledge, but until now in environmental psychology this approach to environmental problems is scarce, whereas in political science and in economics there is empirical and theoretic research about institutional design for solving social dilemmas (for instance E. Ostrom, 1990; E. Ostrom, Gardner, \& Walker, 1994). Psychological research could and should contribute to the goal to design citizenfriendly institutions - institutions that are transparent with respect to the necessity and the con- 
tent of monitoring and sanctioning and salient with respect to the goal to reach common welfare by the prevention of harmful mutual defections.

It is important to note that this role that psychology could take in the context of environmental dilemmas is different from current approaches in environmental psychology that focus on attitude changes and values of the addressees - not only with respect to general environmental problems, but also specifically in environmental dilemmas like, for instance, in the context of biodiversity conservation (Saunders, 2003; Saunders, Brook, \& Myers jr., 2007). From my point-ofview, the appliance of such approaches runs the risk of underestimating the dynamics of the escalation in social dilemmas, when self-interested people continue their (legal) acts and affront people who renounce pursuing their self-interest due to conservation goals. And if enough people are involved in the dilemma like the commons dilemma, approaches without institutions - or, as Hardin (1994) puts it, "without management" - lead to a disaster. "Scale effect rules out the unmanaged commons as an important political possibility in the modern world" (Hardin, 1994, p. 199)

From all that has been revealed by social-dilemma research in the labs and in the field about social values (cf. for instanceYamagishi, 1988), and assuming that environmental values are highly correlated with social values, it can well be speculated that it is a matter of time before people with environmental values and attitudes abandon their positive and sustaining behavior as a result of frustration and fear of being ruined. Many environmental problems are social dilemmas where the individual's attempt to act in a sustainable manner may lead to the loss of his/her livelihood (like, for instance, in fishery conflicts), because acting in a sustainable manner when the others do not means bankruptcy. Therefore, besides psychological approaches concentrating on attitudes and values, in such dilemmas we need institutional solutions. However, we also need psychological expertise to find citizen-friendly institutions that get through to the addressees.

Very few articles about institutional design can be found in psychological databases like PsycInfo (quite recently, a book review by E. Ostrom, 2008 on Rothenstein's "Institutional design and social traps" could be found). Therefore, it is worth mentioning briefly what institutional design is about: "Institutional design is concerned with the choice of decision-making arrangements that will provide the means that are appropriate to the realization [of] specifiable objectives, consequences or ends in view. Any practical man of action who is concerned with organizing the efforts of many individuals in a joint enterprise is necessarily involved in problems of institutional analysis and design" (V. Ostrom \& Hennessey 1972, note to the reader). The decision-making arrangements are organized with rules. "Most of the research that attempts to compare alternative institutional arrangements views institutions as fairly stable sets of commonly recognized formal and informal rules that constrain the behavior of individuals in social interactions" (Weimer, 1995, p. 2f.). In order to guarantee the compliance of the addressees, monitoring and sanctioning are important instruments, and in the context of environmental dilemmas like common pool resources, the adequate design of monitoring and sanctioning is extremely impor- 
tant for the maintenance of common welfare (cf. E. Ostrom, 1990). ${ }^{1}$ Although, in institutional design, controls and sanctioning are such important instruments - especially in coping with social dilemmas, environmental psychology has little to say about the conditions under which the addressees are willing to accept such controls and sanctioning. Indeed, it is a hard task to design monitoring and controls such that they are not an assault on individual autonomy - both from a political and a psychological point-of-view. If institutions are malformed, controls and sanctioning will be perceived as a spurious assault from outside, although they are intended to help to overcome the tragedy and to raise the common welfare.

From the angle of institutional design, monitoring and sanctioning is necessary for the sake of the environment. From the addressees' point-of-view, it should be fair and the functional role in solving a problem that touches them should be obvious. Therefore, we need psychological approaches that take into account both the structure of the dilemma and the psychology of the addressees themselves. In order to come closer to such approaches that consider the three issues already mentioned above, (1) the structure of the dilemma, (2) the knowledge of the addressees about the dilemma, and (3) institutional solutions that are accepted and supported by the addressees, it is worth taking a closer look at such interactions between the structure of the dilemma and the addressees.

The paper is structured as follows. Based on the motivation of this section (1), the next section (2) introduces a mussel-fishery conflict as a relevant illustration. The illustration is used to demonstrate that it makes sense to detach temporal aspects and to concentrate on the formal and structural aspects of the proper dilemma. In section (3), I argue that environmental dilemmas are often extremely difficult, because the stakeholders are in a veil of ignorance about the dilemma structure. The concluding paragraphs of section (3) are devoted to the question of how environmental dilemmas can be solved. Section (4) investigates the scope of reciprocal strategic reactions of stakeholders intended to come to common welfare, demonstrating that the success and applicability of such strategies stands in a close dependence to the complexity and structural form of the dilemma. Section (5) resumes that the scope of aches that focus on changing individuals' behavior is limited, and that complex dilemmas need institutional solutions with controls and sanctioning mechanisms, because a single defector could destroy most or all of the cooperation efforts of many others. Therefore, complex environmental dilemmas need institutional solutions. Based on this insight the article establishes the programmatic vision that psychology engages in institutional ergonomics with the goal of designing citizen-friendly institutions, i.e., to create institutions that are not only efficient with respect to the structural modifications, but also with respect to the functionality, transparency and ease towards the addressees. The engagement in such goals would foster interdisciplinarity of environmental psychology with a significant increase of psychological research in institutional design. Last, but not least, it would help to improve substantially the institutional solutions for environmental dilemmas.

1 In the following, I talk about common welfare, but it is rather obvious that common welfare in the context of environmental dilemmas touches upon sustainability. However, sustainability is also important with respect to temporal aspects that I do not wish to discuss in this article. Therefore, the term common welfare is used in the following. 


\section{An example: The social dilemma in mussel fishery}

For the following illustrations, we consider an idealized mussel-cropping and mussel-fishery conflict in the 1990s that took place in the Wadden Sea, a special ecosystem and part of the North Sea at the Dutch, German and Danish coast. A collapse was threatening, but political attempts to introduce protectorates were extremely difficult due to the resistance of the musselfishermen. "Fisheries continued harvesting the already low stocks, which resulted in a food shortage for birds and, as a result, high bird mortality. This attracted a lot of media attention" (Turnhout, Hisschemöller, \& Eijsackers, 2008). The authors mention that a Dutch newspaper (Handelsblad) even spoke of 'the great cockle robbery' and of an 'ecological disaster'. A German newspaper (taz) described contradicting views from fishermen and scientists on the harmlessness or harmfulness, respectively, of mussel-fishery (Stadie, 1999). "Less is more", is the message from politicians and scientists in such situations. This message is true due to the dilemma structure of the problem: if all fishermen take less, their yields will be higher.

However, from the fishermen's view, this seems like promising a miracle, or like a lie. Their statistics from everyday business give a different answer. The very simplest form of a social dilemma, originally called the "prisoners' dilemma", can demonstrate why this is possible, and it can well be that the fishermen's evaluation is on a sound but incomplete base, and that this is the reason why they come up with the wrong conclusions.

Table 1: The prisoners' dilemma in the context of mussel-fishery

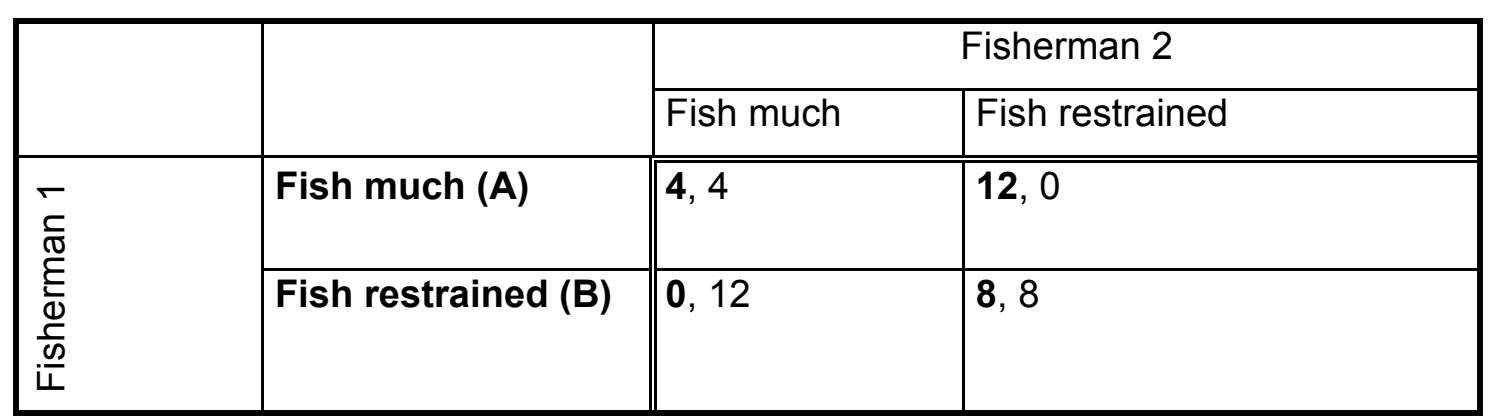

Table 1 gives the very simplest form of an environmental dilemma with the structure of the well known prisoners' dilemma (cf. Luce \& Raiffa, 1957). There are only two stakeholders (individuals or interest groups) and only two choices to select from. Nevertheless, like all environmental dilemmas, the prisoners' dilemma is a serious conflict between individual rationality and collective reason (Poundstone, 1992). The stakeholder may be greedy and therefore decide to fish much, or he may fear that the opponent will be defective and therefore decide to fish much as well. Thus, different motives may lead to defection: the fear of fear, the fear of greed and the greed itself. The prisoners' dilemma illustrates how the structural properties of a situation may lead to severe conflicts of interest and conflicts of motive. It is hard to remain cooperative if the others defect, and cooperative persons are in the pretty neurotic situation of being the naive dogooder (this aspect has already been well described in Hardin, 1968). 
In this highly abstracted and idealized situation, the individual fisherman can either harvest much or he/she can harvest sustainably. However, in contrast to many laboratory experiments with social dilemmas, it is important to note that fisherman 1 usually only has access to the information put in bold in the table. In this case, the conflict described above becomes obvious or at least plausible. In our highly condensed abstraction, the fisherman can only decide "A" (much) or "B" (restrained and sustainable) and in dependence of his decision he gets sometimes 4 or 12 and sometimes 0 or 8 , respectively. ${ }^{2}$ His individual statistics show him that " $A$ " is better than " $B$ ", and so he will pursue to choose " $\mathrm{A}$ " as long as he is under this veil of ignorance about the social interdependencies and the harmful consequences (in contrast to the positive implications of Rawls' (1971) veil of ignorance). By looking at these individual statistics, he quickly learns that " $\mathrm{A}$ " is the better option on the average. In this case, he is blind about the matrix in which he has made his decisions, and therefore his decision is without the intention to harm others, although his decision is related with negative externalities (see also Gifford, 2006, p. 26). However, it is also clear that well-informed people can strategically feign ignorance in order to keep the right to pursue self-interests.

This characterization of the mussel fishery conflict as a social dilemma might remind one of the example of the extinction of king crabs given in Gardner \& Stern (1996). However, in contrast to their analysis, I try to separate the structural aspect of the social dilemma from temporal aspects and temporal uncertainty, in order to concentrate on solutions that are appropriate to overcome the dilemma. This is in contrast to recent publications (like Milfont \& Gouveia, 2006) that mainly base findings on Joireman, Van Lange, \& Van Vugt (2004), who argued that in order to understand inconsistencies between social values and commuting behavior it is necessary to broaden the social dilemma such that it involves both the social conflict and the temporal conflict. Although at first glance their argument contradicts the following analysis, it fits well because their argument is that in the concrete intervention we have to consider both the temporal aspects and the dilemma (in the narrow sense) of an environmental problem. However, and this is in contrast to Joireman, Van Lange, \& Van Vugt (2004), with respect to analysis of the situation it is necessary to disentangle both conflicts, because the temporal aspect of the dilemma needs other interventions than the structural aspect, and that especially the structural aspect of the dilemma necessitates institutional solutions. The same is true for the diagnosis of the situation: The temporal implications need other psychological instruments (like questionnaires) than the structural implications. In many publications about environmental problems, we can find a motivation about the social dilemma, but in the ongoing analysis, the structural aspect gets lost and it is mainly the temporal aspect that is in the focus (like, for instance Miller, 2007, or, in contrast to their claim, Milfont \& Gouveia, 2006). Confounding the temporal and structural aspects can lead to misleading conclusions like the following: "The pursuit of individual self interest causes no problems as long as the total rate at which the fishers catch crabs - determined by the

2 In this and the following examples, I abstain from an interpretation of these numbers as payoffs or yields, because a concrete interpretation is irrelevant for the purpose of this paper to illustrate the interaction of structure and efficacy of different instruments to solve the dilemma. In experiments in the lab, the numbers are usually transformed in payoffs for the participating subjects. 
numbers of fishers times the number each catches - does not exceed the rate at which the crab population can naturally replenish itself' (Gardner \& Stern, 1996, p. 24). This citation stems from a very influential and important book about environmental problems. So much the worse that with respect to environmental dilemmas the authors probably did not see that the pursuit of self-interest in a social dilemma may very well cause problems - even in completely recovering resources without the consequence of the resource itself being menaced. ${ }^{3}$

An example may illustrate this point: the water supply on the Canaries can be understood to be a completely self-replenishing resource; however, the annual total of precipitation varies extremely. Nevertheless, even if the rainfall were constant over the years, it would be a social dilemma. The fresh-water on the Canaries is extracted from the lava. Because of the high permeability of the lava, any barrier is merely temporary and partial, and all extractions of water on each of the Canary Islands is interdependent with other extractions on the same island. The water extraction on each island "exhibits the property of a common" (Ostmann, 1995, p. 2). Due to this underlying social dilemma of a common-pool resource, there are serious problems because different parties (like hotel owners and farmers) extract water with wells and sinter galleries. The investment in devices for water extraction is far beyond the welfare optimum, because in consequence, two parties drain off each other's water supply..

Therefore, it makes sense to separate temporal aspects analytically from structural aspects. This separation makes it possible to classify environmental problems in a $2 \times 2$ crosstab where social dilemma in the narrow sense (yes/no) is crossed with temporal conflict (yes/no).

Table 2: A 2x2-table of environmental problems

\begin{tabular}{|c|c|c|c|}
\hline & & \multicolumn{2}{|c|}{ Social conflict } \\
\hline & & yes (i.e., social dilemmas) & no \\
\hline \multirow{2}{*}{ 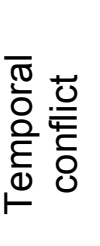 } & yes & Biological resources & $\begin{array}{l}\text { Individual property in } \\
\text { resources }\end{array}$ \\
\hline & no & $\begin{array}{l}\text { Canary-Islands } \\
\text { water conflict }\end{array}$ & $\begin{array}{l}\text { Natural disaster } \\
\text { (such as tsunami) }\end{array}$ \\
\hline
\end{tabular}

In the following, the article at hand concentrates on the structural aspects, i.e., the first column in the $2 \times 2$-classification (cf. table 2).

3 On the other hand, Gardner \& Stern (1996) are completely right with the statement that the size of a population or use of a resource plays an important role whether a dilemma comes up or not - Hardin (2007) tags this as "scale effects". This aspect points to a structural aspect of the environmental problem, and not to a temporal one. Moreover, they are completely right that in many environmental dilemmas with time dynamics the use rate is above the recovering rate of the resource. This points to a time-dynamical aspect of environmental resources, that can also tangle resources without the structure of a social dilemma. 


\section{Environmental social dilemmas typically are under a harmful veil of ignorance}

Many environmental dilemmas are much harder than dilemmas that are investigated in the laboratory, because in the context of many environmental problems with dilemma structures, the stakeholder cannot see the social interdependencies. He does not see the impact of his decision on the outcome of others, and potentially even does not know that others are affected by his decision. Until now we have little empirical knowledge about such "blind” social dilemmas: „By and large, however, this literature [about learning in games] is concerned with learning how to play a game rather than with learning about a game“(Oechsler \& Schipper, 2003, p. 137). A recent study from Nicklisch (2006) examines learning in different $2 \times 2$ games with minimal information setting, but without social-dilemma games. Therefore, it until now it is a reasonable speculation to assume that if the stakeholders have no insight in the structure of the "game", i.e., the social interdependencies of the decisions with other stakeholders, it seems rather obvious that they cannot believe the scientific and political claims that less is more in such situations.

Taking for granted that this assumption is true, any approach in environmental dilemmas should care about data that give information whether the stakeholders are aware of the dilemma in which they are trapped. Solutions for environmental dilemmas should provide for a transparent access to information about the others' behavior and vice versa, about the social interdependencies in the outcomes, and about the whole structure of the dilemma with the welfare optimum and equilibrium based on self-interest falling apart. It is an important step to create transparency about this fact, namely that self-interested decisions lead to sub-optimal decisions in the end, and that cooperative solutions may yield better outcomes. Until now, we have barely data from stakeholders about such knowledge. It is also important to see that a stakeholder's knowledge about the existence of a "win-win situation" would not be sufficient, because it grasps only half of the environmental dilemma, because an understanding of the vulnerability and instability of the win-win situation is also important for the establishment of institutional and sustainable solutions.

The following sections are devoted to the question of how environmental dilemmas can be solved. One important module for the solution of environmental dilemmas is the stakeholder's insight in the dilemma structure. However, as far as I know, until now there is neither environment-psychological research nor social-psychological research with respect to the goal of giving insight into the dilemma that traps stakeholders. As an apparent consequence, there is no nature museum either that could explain to us the dilemma structure of many environmental problems, and that would try to give an answer to the question why stakeholders often make decisions that destroy nature, despite the knowledge about the consequences of their decisions.

Experimental games could be used as an efficient instrument that gives insight in the structure and social interdependencies of environmental dilemmas - for education and mediation as well. We usually only come up with some punching bags and find them guilty of causing the disaster- 
greed and immoderateness. However, it is important to see that the tragedy of environmental destruction may also result from mere struggle for existence in a social dilemma.

Given that the stakeholders see that they are trapped in a social dilemma, there are two paths for the solution of this dilemma: (1) The stakeholders can try to help themselves by making use of reciprocal strategies. Here again, experimental games could also be used to illustrate the virtue of reciprocal strategies. (2) The stakeholders could strive for institutional solutions that afford sustainability in the future. However, often the stakeholders are trapped in the dilemma, and they need institutional solutions. In the following two sections, we will first consider the scope of reciprocal strategies and then the scope of institutional design for the solution of environmental dilemmas.

\section{Reciprocal strategies in environmental dilemmas with different complexity}

If decisions in an environmental dilemma have to be made repeatedly, the stakeholder can make use of reciprocal strategies. Note that in repeated dilemmas, time plays a role because of the repetitions, but this can nevertheless be strictly distinguished from the time dynamics of the resource itself. Therefore, in the structural analysis of the dilemma it is important to consider whether the environmental dilemma situation is a one-shot situation or a situation in a repeated setting with the same stakeholders, because - in contrast to the time dynamics - this makes an important difference from a structural point-of-view. Reciprocal strategies in repeated dilemmas open the stakeholders' floor to defend against defections.

\subsection{Reciprocity in a simple prisoners' dilemma}

In table 1, we found the very simplest form of an environmental dilemma. What happens if the two stakeholders (like the mussel fishermen in the example) have to repeat this game again and again, and one of the stakeholders would like to come to a cooperative solution? Many textbooks on prisoners' dilemmas mention that in that case the stakeholder could try tit-for-tat, a reciprocal strategy that begins with cooperation and then always imitates the action of the opponent in the period before. However, due to the veil of ignorance mentioned before, this strategy could fail in environmental dilemmas. It important that the stakeholder can easily obtain information about both the others' behavior and the others' outcomes, and vice versa; otherwise, reciprocal strategies make no sense.

Axelrod (1984) shows that tit-for-tat is a strategy that never wins any repeated game with a partner - the best result that tit-for-tat can reach with respect to the comparative advantage to the partner is a draw. Nevertheless, tit-for-tat will outperform any other strategy, if the strategy has to complete an iterated (i.e., repeated) prisoners'-dilemma game again and again, with other strategies in a tournament where each strategy is confronted with another to play the iterated 
prisoners' dilemma. In the long run - i.e., in the course of such a tournament - tit-for-tat, on the one hand, ensures the benefits of cooperation and, on the other, avoids being unconditionally exploited. A seemingly paradox characteristic of tit-for-tat is often overlooked: this strategy will never win compared to any opponent or partner in a single iterated prisoners' dilemma. Nevertheless, after many iterated prisoners' dilemmas, it is the winner of the tournament. Two signals of tit-for-tat are important with respect to the attributes of the communication: (1) I want to cooperate and (2) If you do not cooperate with me, I will defend myself with no cooperation. Titfor-tat signals both benevolence and strength, leading to high benefits of cooperation if the other also cooperates (Brandenburger \& Nalebuff, 1996).

(Delahaye \& Mathieu, 1998) introduced some variations in the structure of Axelrod's (1984) tournament that lead to a modified picture, if the structure of the tournament is modified and new strategic options (like abrogation) are introduced. Nevertheless, in concordance to Axelrod, they also conclude that the principles of the successful strategies are as plausible as tit-for-tat. The strategies integrate the concrete structure of the dilemma-rules with the principal ideas of reciprocity.

Taking these conclusions from simulations, and trying to transfer ideas of reciprocity on environmental dilemmas, information policy is extremely important. The addressees need information about the others' reactions and the common consequences of their decisions. Given such information, reciprocal strategies could be helpful to come to solutions of environmental dilemmas that are simple with respect to their complexity. However, slight modifications of complexity can already impose severe embarrassments .to reciprocal strategies. I will discuss some of these modifications in the next subsections: asymmetry (4.2.), scale effects (4.3.) and nonlinearity of the common result (4.5). In section (4.4) I argue that on the other hand an enrichment of environmental dilemmas with graduated options can alleviate the applicability of reciprocal strategies.

\subsection{Reciprocity in case of asymmetry}

Even this simplest form of an environmental dilemma with two stakeholders and two options, respectively, can be enriched in complexity by introducing asymmetry. In this case, it is much harder to reach welfare and cooperation. Due to allocation conflicts that come up, the success of tit-for-tat is much worse. Distributive justice plays a crucial role in conflicts with such asymmetries. 
Table 3: The asymmetric dilemma

\begin{tabular}{|c|c|c|c|}
\hline & & \multicolumn{2}{|c|}{ Fisherman 2} \\
\hline & & Fish much & Fish much \\
\hline \multirow{2}{*}{ 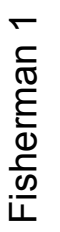 } & $\begin{array}{l}\text { Fish much } \\
\qquad(A)\end{array}$ & 4,6 & 12,0 \\
\hline & $\begin{array}{l}\text { Fish restrained } \\
\text { (B) }\end{array}$ & 0,18 & 8,12 \\
\hline
\end{tabular}

A reason for such asymmetries could be different costs of access to the resource, such that one fisherman ends up better off both in mutual defection and in mutual cooperation. Due to this asymmetry, the "weaker" or poorer fisherman with worse conditions may desire to equalize the disadvantage by casual defections. Data from the lab indicate such an interpretation. In asymmetric prisoners' dilemmas the phases of cooperation are much shorter and long phases of cooperation are extremely rare compared to the symmetric dilemmas (Beckenkamp, Hennig-Schmidt, \& Maier-Rigaud, 2006). If the stakeholder in the stronger position reacts to the defection of the weaker stakeholder with tit-for-tat, he undermines the equalization-idea of the weaker stakeholder. In such cases, the underlying idea of tit-for-tat to maximize common welfare comes in conflict with subjective justice-sentiments concerning equality. Magen (in preparation) assumes that dilemma experiments with unequal endowments reveal the ambiguity of fairness criteria in almost every experiment about asymmetric social dilemmas (see also Magen, 2006).

Due to such justice-conflicts, there is a special dynamic in asymmetric prisoners' dilemmas. Structural solutions that help to maintain welfare may become necessary. A simple solution could be to create a platform for negotiations about side-payments. Another solution could be to keep the situation deliberately opaque with respect to the benefits (such a solution can often be found with respect to payments of employees). However, this again may yield the problem of "blind" dilemmas and the veil of ignorance described before. Another solution consists in giving good reasons that justify the inequalities, thus enriching the issue about distributive justice with issues about procedural justice (Ittner \& Ohl, 2006).

\subsection{Reciprocity and scale effects}

Until now, our focus was on environmental dilemmas with only two stakeholders involved. However, in most of the environmental dilemmas there are more than two stakeholders involved. A possible extension of the 2-person-dilemma is as follows. In this example, we assume that there are 9 mussel-fishermen, and each of them decides either to fish much or to restrain his fishing (cf. table 3). 
Table 4: A $n$-person social dilemma $(n=9)$

\begin{tabular}{|c|c|c|c|c|c|c|c|c|c|c|}
\hline & & \multicolumn{9}{|c|}{ Number of others fishing restrained } \\
\hline & & 0 & 1 & 2 & 3 & 4 & 5 & 6 & 7 & 8 \\
\hline \multirow{2}{*}{ 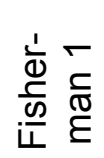 } & Fish much & 4 & 5 & 6 & 7 & 8 & 9 & 10 & 11 & 12 \\
\hline & Fish restrained & 0 & 1 & 2 & 3 & 4 & 5 & 6 & 7 & 8 \\
\hline
\end{tabular}

If all stakeholders cooperate, each of them earns 8; if, however, four stakeholders cooperate and fish restrainedly, then the fisherman under consideration receives 8 if he fishes much and 4 if he fishes sustainably. Please note that the payoffs in the corners in the table of this 9-person dilemma correspond to the simple 2-person dilemma (table 1). The situation can be graphically represented as follows (cf. figure 1):

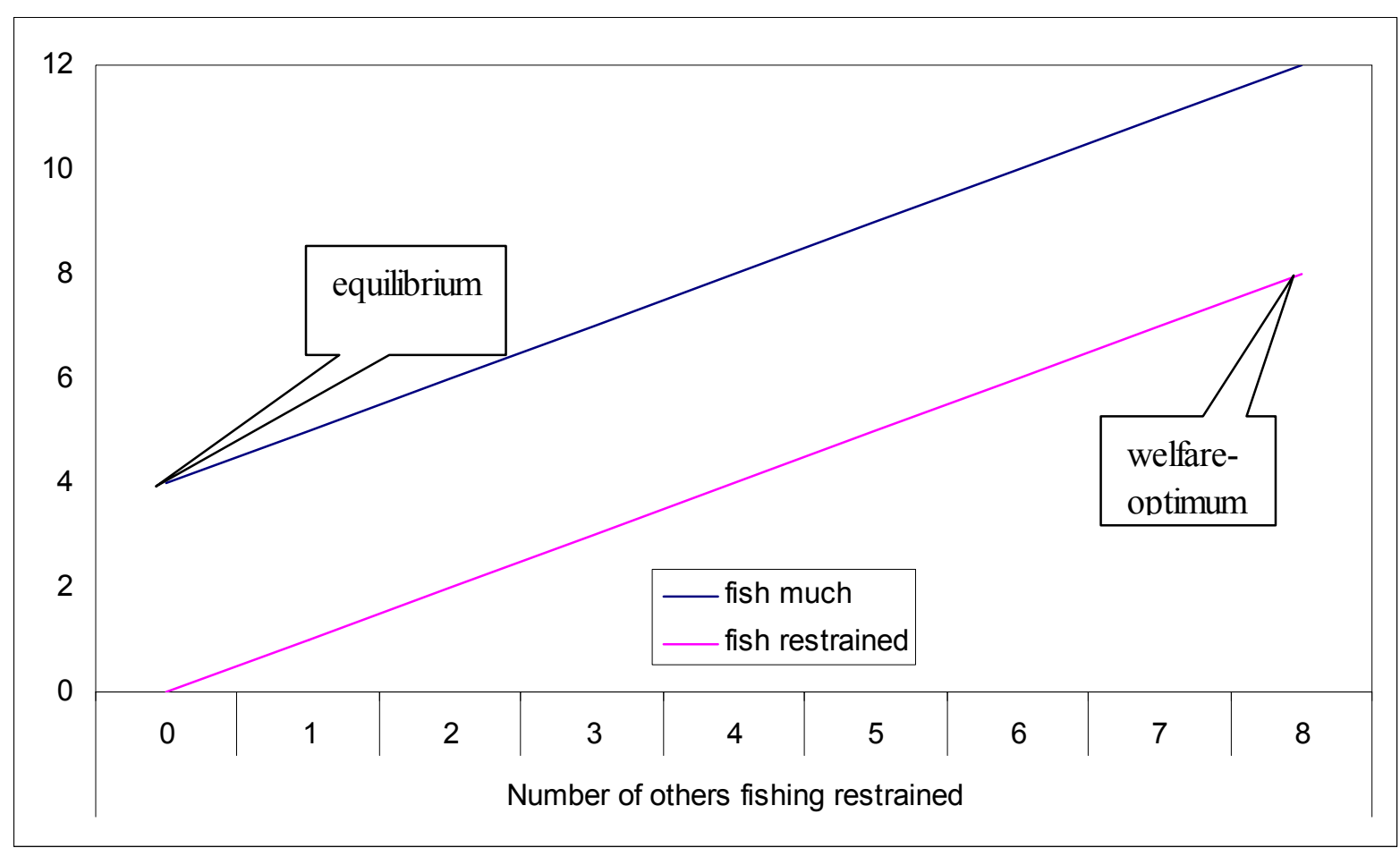

Figure 1. A graphical representation of the N-Person-dilemma (cf. table 3)

The two lines in this figure represent the two decisions that the fisherman under consideration can make. The upper line gives his result (depending on how many others restrained) if he fishes much, and the lower line if he fishes sustainably. Like in the 2-person dilemma, the fisherman is always better off if he fishes much, but if this rational consideration is made by all fishermen, they will end up with 4 instead of 8 for each of them, if all cooperate (see also van Lange, Lie- 
brand, Messick, \& Wilke, 1992). Therefore, the game-theoretic equilibrium falls apart from the welfare optimum, and the welfare optimum is instable because there is always the temptation to defect for each of the fishermen.

Do reciprocal strategies make sense in this simplest form of an N-person-dilemma? No, because how to make use of tit-for-tat, if two others fish much and all the others fish sustainably? If, in reaction to the defection, those fishermen also fished much, this would make things still worse, because if all of the fishermen followed this reciprocal idea, there would be at least 7 persons in the next period who fish much, and if the other two continued to fish much, they would all be in the inefficient and unsatisfactory equilibrium. This non-applicability of reciprocal strategies in such simple N-person game is one reason why cooperation rates usually are much poorer in repeated N-person dilemmas than in repeated 2-person dilemmas. Even worse, communication is also problematic, because with the growing number of participants in the dilemma, communication channels and rules are necessary.

Therefore, it makes sense to strive for institutions to solve this kind of environmental dilemma. However, such institutions must not necessarily come from outside or top-down, because historic examples and current cases show that self-governance can be possible (E. Ostrom, 1990). However, Ostrom's argument should not be overlooked that in these case studies, successful selfgovernance always includes monitoring and sanctioning - even in small groups governing a common-pool resource. ${ }^{4}$ Nevertheless, self-governance may outperform governance from outside, because the efficiency of controls and the adequacy of sanctions are highly dependent on context specificities. Often, nobody knows such specificities better than the addressees of institutions themselves.

\subsection{Measure for measure: Reciprocity with graded options of the stakeholders}

Increasing the option space of the participants may help to make reasonable use of reciprocal strategies, for instance if each participant, instead of choosing between two options, can choose an exploitation rate between 0 and 100. In concrete examples and resources like mussels, it is not a trivial task to see what $100 \%$ exploitation (i.e., $0 \%$ cooperation) and $0 \%$ exploitation (i.e., $100 \%$ cooperation) would mean. ${ }^{5}$ Given that the relevant poles have been identified - an exploitation rate of $0 \%$ corresponds to the sustainable fishing option, and the exploitation rate $100 \%$ corresponds to fishing much. In literature, such experimental games with extended option spaces are called public-good games. The 9-person game in figure 1 would be such a public-good game if parallel lines between the upper and lower line were additional options. Therefore, the gametheoretic structure with the discrepancy between welfare optimum and equilibrium is maintained, and the upper line is still the best option from a self-interested point-of-view. However, those stakeholders who want to come closer to the welfare optimum get a strategic possibility to make

$4 \quad$ Again, this issue stands in contrast to Gardner \& Stern (1996, p. 28f).

5 One reason for this might be the quadratic pay-off function, as we will see in the next section. 
reasonable use of tit-for-tat, by taking the average cooperation-rate of the others as the benchmark for the own decision. So, for instance, if the others cooperated before with $50 \%$, the stakeholder would decide to cooperate with $50 \%$ as well, if he wants to make use of tit-for-tat in this N-person situation.

Above that, this extension of options opens up the action-space for light variations of tit-for-tat even in 2-person-dilemmas. Instead of paying the other out in his own coin, now it is also possible to lightly attenuate the own reaction. For instance, if the other cooperated with $40 \%$, tit-fortat reacts by cooperating with $40 \%$ also, but it is also possible to cooperate a little bit more, for instance with $45 \%$. In psychology, this reciprocal strategy is called tit-for-tat+ (van Lange, Ouwerkerk, \& Tazelaar, 2002); in economics, it is called "measure for measure (Selten, Mitzkewitz, $\&$ Uhlich, 1997). The small leap of faith provides the chance of escaping from tit-for-tat traps like the arms race, and it can compensate for failures in communication or accomplishment of actions. Van Lange et al. demonstrated that this strategy is perceived as strong as tit-for-tat, but with respect to other positive psychological attributions and to the ability to de-escalate it is superior.

Measure for measure seems also to make sense in N-person dilemmas, although empirical studies are still seldom (Beckenkamp, 1999; E. Ostrom et al., 1994). These studies demonstrate that in experimental common-pool resources measure for measure is seldom used. In the fishery example, the stakeholder who would want to make use of measure for measure would have to take the average quota of the others as a base for his own decision. Sometimes, politics seem to have such a strategy in mind when political goals in international negotiations are pursued, and an example is given by raising the bars for environmental goals higher than others do. By doing that in a way that is adapted to the current level, one can avoid being unconditionally exploited in the dilemma, and nevertheless signalize that one wants to achieve higher goals and better cooperation in the dilemma.

However, all the same it is likely that measure for measure strategies are less successful in Nperson dilemmas compared to 2-person dilemmas. Even if we can take for granted that communication is clear and visible, so that the signals of willingness to cooperate are unambiguous, it is harder to affect a group of stakeholders than to affect a single other stakeholder by making merely use of that strategy. On the other hand, it can well be that a rather mild institution that could not reasonably reach welfare goals alone works well if part of the participants make use of such strategies. Again, this principle is true for international negotiations. The sanctions that can be imposed against defecting countries are often far from bringing self-interested stakeholders to cooperation for environmental goals. However, besides the mild sanctions there often are stakeholders who pursue common welfare goals and who make use of measure for measure in order to signal that they want to improve the environment, but do not want to do this without the contribution of stakeholders who have behaved in a self-interested fashion until now. 


\subsection{Measure for measure: quadratic resource dilemmas}

Unfortunately, the structure of environmental dilemmas is much more complicated and complex than sketched until now, even if we refrain from considering time dynamics. Usually, environmental resources can be both overexploited and underused, so that it is not always clear whether a certain action is good for the environment or not. From a structural point-of-view, this property of many environmental resources rests upon the non-linearity of the yields (in all the above examples, the yields were linear) in dependence of the stakes. The yields of many resources and the resulting characteristics of the environmental dilemma can well be modeled by using quadratic functions (cf. Beckenkamp, 2006; Ostmann, 1995), particularly fishery conflicts at a certain point in time (cf. Hartwick \& Olewiler, 1998) - again, we want to disregard time dynamics, because time dynamics may change the shape of the quadratic function, but not the principle quadratic characteristic of the dilemma at a certain point in time.

This example illustrates that kind of dilemma: four fishermen can send up to ten cutters for harvesting mussels on the ground of the sea. Figure 2 gives the yield in dependence of the sum of the trawlers sent in total.

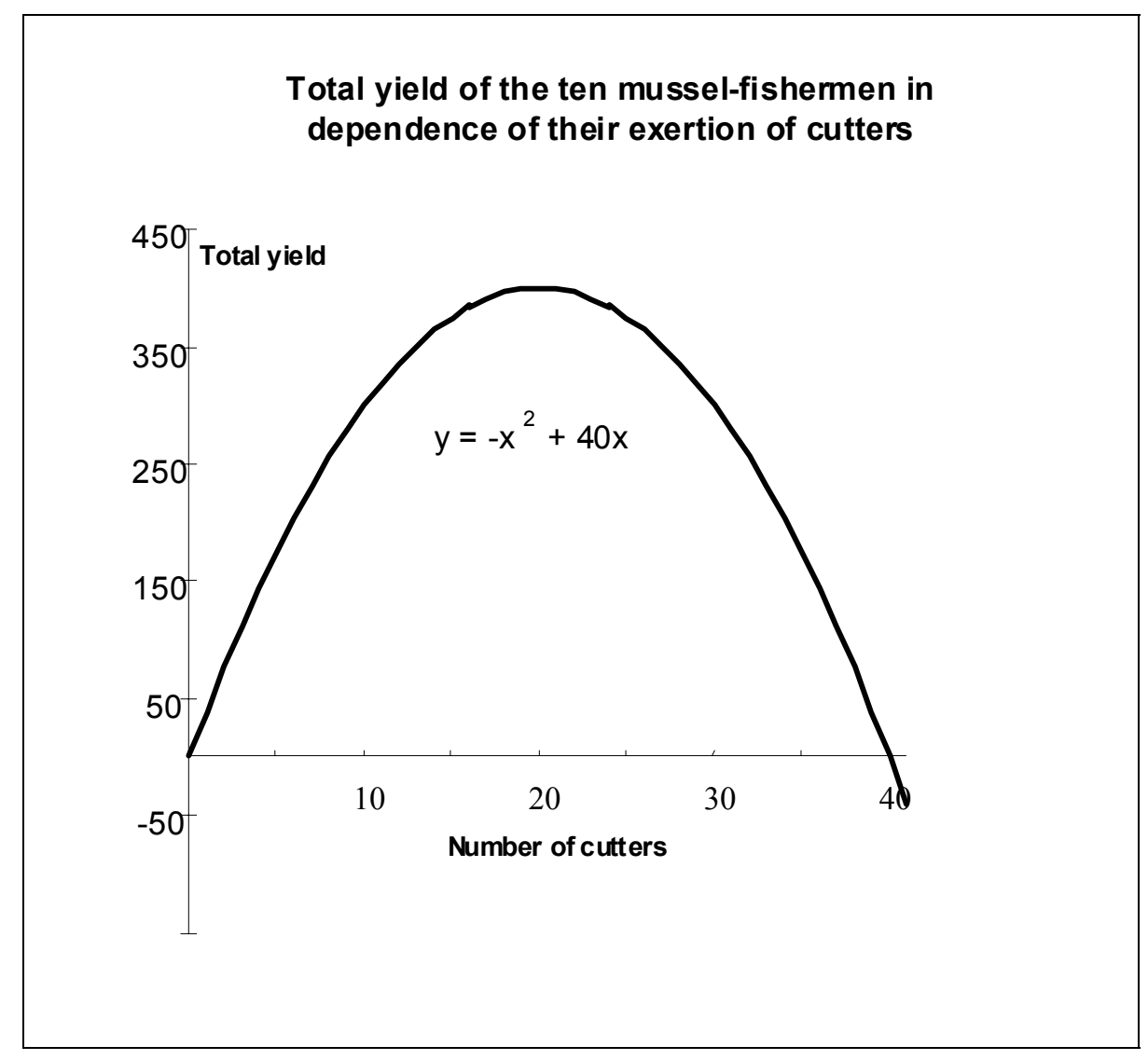

Figure 2. A graphical illustration of a quadratic environmental dilemma 
The function shows that the maximal yield of 400 is achieved with 20 cutters. If each of the four stakeholders sent 5 cutters, then each of them would gain 5/20*400=100. However, this welfare optimum is not stable, because each of the stakeholders could make the following reasoning at this point. "I should send one more cutter out, because then 21 cutters would be at sea, the total yield would be 399 and I would gain $6 / 21 * 399=114$. If I sent 10 cutters, I would even earn 150." The tragedy arises again, because each of the stakeholders could reason in such a way about the best response, with the result that they end up in the equilibrium with 32 cutters in total and a total yield of $256 .{ }^{6}$ This is only $64 \%$ of the welfare optimum, so that each of them would have to bear $36 \%$ loss from their original gain. Who, from the stakeholders' point-of-view, is responsible for the tragedy, when they are not aware of the dilemma in which they are trapped? It seems rather obvious that in such slightly more complex dilemmas the application of measure for measure strategies becomes extremely difficult. In contrast to the linear dilemmas given before, in this dilemma a single defector can destroy all the attempts of cooperation of the other stakeholders: if three fishermen cooperate and use only 5 trawlers each, the fourth fisherman could send all he has and make his profits at the disadvantage of the other three. Unfortunately, this kind of environmental dilemma is rather typical of many resource dilemmas. It is an environmental dilemma that needs institutional support for a sustainable solution.

Nevertheless, measure for measure strategies might be useful even in such cases, for example in order to come to institutions that could solve the problem. Again, it is a necessary precondition that the signals and the communication of that strategy are salient. In such a case, the strategy would also help the respective stakeholder who makes use of it to build up a reputation. It is mostly uncontroversial that such a reputation can help to build up trust - an important first step to solve the dilemma (Liberman, Samuels, \& Ross, 2003; Wilson, 1985). Making use of the strategy can also help to get support from other stakeholders to build an institution made to solve or to attenuate the environmental dilemma. To count only on reputation without institutional lining, however, is dangerous, because reputation can be used to prepare high stake deceptions. In eBay, such cases could often be found; in consequence, they finally led to the implementation of much more institutional trust-systems within the eBay-platform.

\section{Institutional ergonomics: Creating citizen-friendly institutions}

The last section investigated the scope of reciprocal strategic reactions of stakeholders intended to come to common welfare, demonstrating that the success and applicability of such strategies stands in close dependence to the complexity and structural form of the dilemma. It showed that particularly resource dilemmas like the mussel-fishery are extremely vulnerable to defections coming from minorities. In such cases, institutional solutions are necessary that help to stabilize mutual cooperation. This section considers institutional solutions with controls and sanctioning mechanisms, and argues that psychology should get in the research about institutional design. 
Empirical experiences demonstrated that in complex environmental dilemmas, it is hard to convince the individual of their individual impact on the destruction of their basis of existence. Many environmental studies report long-lasting mediation processes to overcome environmental dilemmas (cf., for instance Ohl et al., 2008).

Focusing on the structural aspect could lead to new strategies in the mediation process. Potentially, experimental games could help to illustrate the trap stakeholders are locked in and thus to accelerate mediation processes. Experimental games can fill this gap. Why not play a dilemma game about mussel-fishery with the stakeholders themselves, - a game that is adapted to their situation that demonstrates that they could achieve a win-win constellation, but that this constellation is extremely vulnerable? This would be a completely new approach, both in psychology and in institutional design. Experimental games can be used both for data acquisition and for mediation in the conflict in order to come to a well-integrated institutional design.

The target-oriented data acquisition with respect to a game-theoretic valid model takes several steps. The first step is the identification of the relevant stakeholders within the environmental dilemma. How many players are there in the game or, accordingly, how many stakeholders are there in the environmental dilemma? This provides the relevant stakeholders of our games, sketched out before. Ideally, such studies should be shaped in such a way that the number of different interest groups is small, such that a rather big conflict (as, for instance, the whole Wadden Sea conflict is) can be broken down into manageable sub-conflicts. Therefore, instead of integrating the conflict between tourism, mussel-fishery, other forms of fishery and industry in one game, it would make sense to take only the fishery conflict as one game and to map other conflicts in other games, such that each conflict can be put on its own agenda.

One the stakeholders of such a manageable conflict have been identified, the second step would be to try to identify the relevant action space of the respective stakeholders; this corresponds to the rows and columns in the examples given before. Then, in the last step, the ranks in the evaluation of the different combinations of actions for each of the stakeholders should be elevated. This corresponds to the cell entries in the tables of the examples before.

With respect to mussel fishery, the scientific board ETG (Ecotarget group; cf. Turnhout et al., 2008) could identify relevant stakeholders. These stakeholders could be addressed and asked about the options they have and their preferences. The stakeholders and their options could be mapped in the matrix and the stakeholder could be asked afterwards about their preferences in the outcomes in the matrix, for instance by asking them to rank-order the following outcomes:

- You are fishing much, and the others are fishing sustainably

- You are fishing sustainably and the others are fishing sustainably

- You are fishing much and the others are fishing much

- You are fishing sustainably and the others are fishing much 
The answers can be used to identify the games the stakeholders play within their relevant options with each other. When the "game" is identified, it can be used in confrontation with the stakeholders in order to check the validity of the diagnostic process. If the game fits well, the diagnosis of the environmental problem (which can be an environmental dilemma, but it could also have a different, non-dilemma structure) is finished and the same game can be used to illustrate the structural problem beyond to the stakeholders. If the game does not fit well, the diagnosis itself should be evaluated with respect to the differences between the answers the stakeholders gave and the denial of the stakeholders with respect to the game that has been identified on the basis of their answers.

Making use of experimental games in environmental dilemmas in order to come to a valid diagnosis of conflicts is one issue where environmental psychology could tie in with institutional design. However, until now, institutional design is mainly a topic in political science, law and economics. In social conflicts, psychology is mainly used for mediation and strategies of attitude and value change in the addressees.

However, psychology could even do more within this domain, because the diagnosis can be a solid fundament for the support in interventions. Many environmental problems are complex social dilemmas (Brock \& Xepapadeas, 2003) that need both institutional solutions and insight into and support of such solutions by the addressees. Given a valid diagnosis of the "game", i.e., a game-theoretic representation of the environmental dilemma that is not denied by the stakeholders with respect to its relevance and validity in relation to their situation, it can be used as an illustration for the stakeholders about their strategic situation. It could also be useful for insights about the structural blindness of the stakeholders, before they played the game. In case of a social dilemma, the game can be used to illustrate that the stakeholders could strive for a win-win constellation - however, a win-win situation that is extremely reactive to defections. This raises the question of how to stabilize the win-win-constellation, and thus the purpose of institutions can be illustrated, and the games used to discuss and prototypically implement different institutional solutions. Both the diagnosis of the environmental dilemma and the intervention with a preparation of institutional solutions are tasks that fit psychological research goals and applications very well. Therefore, psychology could have a much better impact on institutional design. Beyond doubt, this is an ambitious task. Until now, psychology is mainly ignored, probably with fatal consequences for the environment, because according to current research in psychology and other disciplines it can be expected that the success of institutions in solving social dilemmas crucially depends on the addressees' interpretation of the institutions.

This leads to a further research issue within this integration in interdisciplinary research about institutional design. Environmental psychology researches the circumstances under which institutions are either seen as an intrusion from outside or as a help in solving a pressing problem. Institutions can only be successful if the latter is true, and psychology can contribute with research and know-how. This research is closely related to psychological research about justice and justice sensitivity (like, for instance, Gollwitzer, Schmitt, Schalke, Maes, \& Baer, 2005). 
Above that, psychological research should not only be concerned with improving institutions, but also with changing the impact of institutions on internalized norms. Both injunctive norms and descriptive norms are favorable for the solution of environmental dilemmas, and descriptive and injunctive norms are in a positive interaction (Thogersen, 2008). Institutions probably play an important role in inducing cooperation in environmental dilemmas by modifying the belief that others cooperate (descriptive norm), and by modifying the belief that relevant others expect one to cooperate (injunctive norms). Within the domain of institutional design, psychological research about the role of institutions on the internalization of descriptive and injunctive norms is important. Under normal circumstances, controls and sanctions are usually bad. However, controls and sanctions can also be important to give positive signals on what society expects from the individual and what the individual can expect others to do.

This issue is closely connected to the question of what role a structural insight into the dilemma problem plays, which the institution is about to solve? Should the research demonstrate that institution acceptance crucially depends on the insight into the problem the institution is about to solve, this research would be extremely important Although psychology is rich in relevant knowledge about how to give addressees insight in environmental problems, it does not yet have much experience about different methods that facilitate the insight into environmental social dilemmas. This research could tie into a long tradition in psychological research about social dilemmas (cf. Liebrand, van Lange, \& Messick, 1996).

Institutions should be easy to understand, and it should be easy to understand what institutions expect in a given situation. Institutional design should turn to the question of institutional ergonomics (Beckenkamp, 2004), and by doing that, psychology could earn an important and significant role. In political science, it is well known that institutions that are made to solve environmental social dilemmas - or, to be more specific, common-pool resource problems - have to be transparent, comprehensible and fair. According to Dietz, Ostrom and Stern (2003) and E. Ostrom (1990), this is an essential feature of successful self-governance. The intensified integration of environmental psychology in institutional design would be in the interest of sustainable solutions in environmental dilemmas.

\section{Acknowledgements}

I thank the Krekeler foundation which generously supports my research on social dilemmas in biodiversity issues. I am also very grateful to Brian Cooper for the linguistic support. I also thank Christoph Engel, Jan Multmeier, Felix Bierbrauer, Cornelia Ohl, Heidi Ittner, Stephan Dickert, Darius Geis and Frank Maier-Rigaud for comments on earlier versions of this paper. 


\section{References}

Axelrod, R. (1984). The Evolution of Cooperation. New York: Basic Books.

Beckenkamp, M. (1999). The use of "measure-to-measure" strategies in commons dilemmas. Havat Habaron, Israel: Presentation at the VIIIth International Conference on Social Dilemmas.

Beckenkamp, M. (2004). Institutional design in CPR-problems: a fruitful field for the crossfertilization between economics and psychology. Paper presented at the IAREP/SABE 2004, Philadelphia, Drexel University.

Beckenkamp, M. (2006). A Game Theoretic Taxonomy of Social Dilemmas. Central European Journal of Operations Research(3), 1-17.

Beckenkamp, M., Hennig-Schmidt, H., \& Maier-Rigaud, F. (2006). Cooperation in symmetric and asymmetric prisoner's dilemma games (No. 2006/25). Bonn: Max-Planck-Institute for Research on Collective Goods. 2006/25.

Brandenburger, A. M., \& Nalebuff, B. J. (1996). Co-opetition. New York: Doubleday.

Brock, W. A., \& Xepapadeas, A. (2003). Valuing biodiversity from an economic perspective: A unified economic, ecological, and genetic approach. American Economic Review, 93(5), $1597-1614$.

Delahaye, J.-P., \& Mathieu, P. (1998). Altruismus mit Kündigungsmöglichkeit. Spektrum der Wissenschaft(Februar 98), 8-14.

Dietz, T., Ostrom, E., \& Stern, P. C. (2003). The struggle to govern the commons. Science, 302, 1907-1912.

Epstein, R. A. (1997). Simple Rules for a Complex World: Harvard University Press.

Gardner, G. T., \& Stern, P. C. (1996). Environmental Problems and Human Behavior. Needham Heights, MA: Allyn \& Bacon.

Gifford, R. (2006). A general model of social dilemmas. International Journal of Ecological Economics and Statistics, 5, 23-40.

Gollwitzer, M., Schmitt, M., Schalke, R., Maes, J., \& Baer, A. (2005). Asymmetrical effects of justice sensitivity perspectives on prosocial and antisocial behavior. Social Justice Research, 18, 183-201.

Hardin, G. (1968). The Tragedy of the Commons. Science, 162, 1243-1248.

Hardin, G. (1994). The Tragedy of the Unmanaged Commons. Trends in Ecology and Evolution, 9(5), 199. 
Hardin, G. (2007). The Tragedy of the Unmanaged Commons. In D. J. Penn \& I. Mysterud (Eds.), Evolutionary perspectives on environmental problems (pp. 105-107). New Brunswick, NJ: Transaction Publishers.

Hartwick, J. M., \& Olewiler, N. D. (1998). The Economics of Natural Resource Use (2nd ed.). New York: Addison-Wesley.

Ittner, H., \& Ohl, C. (2006). Playing fair within climate protection policy? - Bringing together psychological and economic methods. ICFAI Journal for Environmental Law (IJEL), 1, 34-53.

Joireman, J. A., Van Lange, P. A. M., \& Van Vugt, M. (2004). Who Cares About the Environmental Impact of Cars? Those With an Eye Toward the Future. Environment and Behavior, $36(2), 187-206$.

Liberman, V., Samuels, S. M., \& Ross, L. (2003). The name of the game: Predictive power of reputations versus situational labels in determining prisoners's dilemma game moves. Personality and Social Psychology Bulletin, 30, 1175-1185.

Liebrand, W. B. G., van Lange, P., \& Messick, D. M. (1996). Social Dilemmas. In A. S. R. Manstead \& M. Hewstone (Eds.), The Blackwell Encyclopedia of Social Psychology (1 ed., pp. 546-551). Oxford: Blackwell.

Luce, R. D., \& Raiffa, H. (1957). Games and Decisions. New York: Wiley.

Magen, S. (2006). Zur Interaktion von Recht und sozialen Normen bei der dezentralen Bereitstellung von Gemeinschaftsgütern (No. 133). Bonn: Max-Planck-Institute for Research on Collective Goods. 133.

Magen, S. (in preparation). Gerechtigkeitserwartungen im Recht. Unpublished Habilitationsschrift, Universität Bonn.

Milfont, T. L., \& Gouveia, V. V. (2006). Time perspective and values: An exploratory study of their relations to environmental attitudes. Journal of Environmental Psychology, 26(1), 72 82.

Nicklisch, A. (2006). Perceiving strategic environments: An experimental study of strategy formation and transfer. (No. 2006/17). Bonn: Max-Planck-Institute for Research on Collective Goods. 2006/17.

Oechsler, J., \& Schipper, B. (2003). Can you guess the game you are playing? Games \& Economic Behavior, 43, 137-152.

Ohl, C., Johst, K., Meyerhoff, J., Beckenkamp, M., Grüsgen, V., \& Drechsler, M. (2008). Long Term Socio-Ecological Research (LTSER) in the context of biodiversity protection - A 
Complex systems approach for the study of dynamic human-nature interactions. Ecological Complexity, Special Issue "Eco Summit 2007".

Ostmann, A. (1995). Water Management on the Eve of Crisis - The case of The Canary Islands. Saarbrücken.

Ostrom, E. (1990). Governing the Commons. Cambridge: Cambridge University Press.

Ostrom, E. (2008). Review of Social traps and the problem of trust: Theories of institutional design. Political Psychology, 29(1), 136-139.

Ostrom, E., Gardner, R., \& Walker, J. (1994). Rules, Games and Common Pool Resources. Ann Arbor, Mich.: University of Michigan Press.

Ostrom, V., \& Hennessey, T. (1972). Institutional Analysis and Design. Bloomington: Indiana University.

Poundstone, W. (1992). Prisoner's Dilemma: John von Neumann, Game Theory, and the Puzzle of the Bomb. New York: Doubleday.

Rawls, J. (1971). A Theory of Justice. Cambridge: The Belknap Press of Harvard University Press.

Saunders, C. (2003). The emerging field of conservation psychology. Human Ecology Forum, $10(2), 137-149$.

Saunders, C., Brook, A., \& Myers jr., O. E. (2007). Using psychology to save biodiversity and human well-being. Conservation Biology, 20(3), 702-705.

Selten, R., Mitzkewitz, M., \& Uhlich, G. R. (1997). Duopoly Strategies Programmed by Experienced Players. Econometrica, 65(3), 517-555.

Stadie, V. (1999, 13. Oktober). Krabbenfischer fangen nicht nur Krabben. taz, p. 17,

Thogersen, J. (2008). Social norms and cooperation in real-life social dilemmas. Journal of Economic Psychology, 29(4), 458-472.

Turnhout, E., Hisschemöller, M., \& Eijsackers, H. (2008). Science in Wadden Sea policy: from accommodation to advocacy. Environmental Science \& Policy, 11(3), 227-239.

van Lange, P. A. M., Liebrand, W. B., Messick, D. M., \& Wilke, H. A. M. (1992). Social Dilemmas: The State of the Art. In W. B. Liebrand, D. M. Messick \& H. A. M. Wilke (Eds.), Social Dilemmas: Theoretical Issues and Research Findings (1 ed., pp. 3-28). Oxford: Pergamon Press.

van Lange, P. A. M., Ouwerkerk, J. W., \& Tazelaar, M. J. A. (2002). The Benefits of Generosity. Journal of Personality \& Social Psychology, 82(5), 768-780. 
Weimer, D. L. (1995). Institutional Design: Overview. Boston: Kluwer.

Wilson, R. (1985). Reputation in Games and Markets. In A. E. Roth (Ed.), Game theoretic models of bargaining (pp. 27-62). Cambridge: Cambridge University Press.

Yamagishi, T. (1988). Seriousness of Social Dilemmas and the Provision of a Sanctioning System. Social Psychology Quarterly, 51, 32-42. 


\section{Preprints 2008}

229. Felix Bierbrauer / Lydia Mechtenberg: Winners and Losers of Early Elections: On the Welfare Implications of Political Blockades and Early Elections. 2008/50.

228. Andreas Glöckner / Stephan Dickert: Base-rate Respect by Intuition: Approximating Rational Choices in Base-rate Tasks with Multiple Cues. 2008/49.

227. Andreas Glöckner / Steffen Moritz: A Fine-grained Analysis of the Jumping to Conclusions Bias in Schizophrenia DataGathering, Response Confidence, and Information Integration. 2008/48.

227. Martin Hellwig: A Generalization of the Atkinson-Stiglitz (1976) Theorem on the Undesirability of Nonuniform Excise Taxation. 2008/47.

226. Carsten Burhop: The Underpricing of Initial Public Offerings in Imperial Germany, 1870-1896. 2008/46.

225. Martin Hellwig: A Note on Deaton's Theorem on the Undesirability of Nonuniform Excise Taxation. 2008/45.

224. Martin Hellwig: Zur Problematik staatlicher Beschränkungen der Beteiligung und der Einflussnahme von Investoren bei großen Unternehmen. 2008/44.

published in: Zeitschrift für das gesamte Handelsrecht und Wirtschaftsrecht 172 (2008), 768 - 787

223. Martin Hellwig: Systemic Risk in the Financial Sector: An Analysis of the Subprime-Mortgage Financial Crisis. 2008/43.

222. Andreas Glöckner / Ann-Katrin Herbold: Information Processing in Decisions under Risk: Evidence for Compensatory Strategies based on Automatic Processes. 2008/42.

221. Jörn Lüdemann / Stefan Magen: Effizienz statt Gerechtigkeit? 2008/41.

220. Christoph Engel: Die Bedeutung der Verhaltensökonomie für das Kartellrecht. 2008/40.

219. Felix Bierbrauer: A unified approach to the revelation of public goods preferences and to optimal income taxation. 2008/39.

218. Carsten Burhop / Thorsten Lübbers: Incentives and Innovation? R\&D Management in Germany's High-Tech Industries During the Second Industrial Revolution. 2008/38.

217. Andreas Nicklisch / Tobias Salz: Reciprocity and status in a virtual field experiment. 2008/37.

216. Andreas Glöckner / Christoph Engel: Can We Trust Intuitive Jurors? An Experimental Analysis. 2008/36.

215. Jörn Lüdemann: Wettbewerb und Regulierung in der Telekommunikation. Das Telekommunikationsrecht vor den Herausforderungen dynamischer Märkte. 2008/35.

published in: Jörn Lüdemann (Hrsg.), Telekommunikation, Energie, Eisenbahn - Welche Regulierung brauchen die Netzwirtschaften? Tübingen (Mohr Siebeck) 2008, S. 69-99

214. Martin Beckenkamp: Playing strategically against nature? - Decisions viewed from a game-theoretic frame. 2008/34.

213. Christoph Engel: Preponderance of the Evidence versus Intime Conviction. A Behavioural Perspective on a Conflict between American and Continental European Law? 2008/33.

212. Kristoffel Grechenig: Schadenersatz bei Verletzung von $\S 14 \mathrm{WpHG}$ ? Insiderhandel mit positiver und negativer Information. 2008/32.

211. Felix Bierbrauer: Optimal Income Taxation, Public Goods Provision and Robust Mechanism Design. 2008/31.

210. Hans-Theo Normann: Vertical Integration, Raising Rivals’ Costs and Upstream Collusion. 2008/30. forthcoming in: European Economic Review

209. Martin Hellwig: Competition Policy and Sector-Specific Regulation for Network Industries. 2008/29.

forthcoming in: X. Vives (ed.), "Competition Policy in the EU: Fifty Years on from the Treaty of Rome" Oxford University Press. 
208. Niels Petersen: Rational Choice or Deliberation? - Customary International Law between Coordination and Constitutionalization. 2008/28.

forthcoming in: Journal of Institutional and Theoretical Economics 165 (2009)

207. Stephen Broadberry / Carsten Burhop: Resolving the Anglo-German Industrial Productivity Puzzle, 1895-1935:

A Response to Professor Ritschl. 2008/27.

forthcoming in: Journal of Economic History

206. Niels Petersen: Demokratie und Grundgesetz - Veränderungen des Demokratieprinzips in Art. 20 Abs. 2 GG angesichts der Herausforderungen moderner Staatlichkeit. 2008/26.

forthcoming: Jahrbuch des öffentlichen Rechts der Gegenwart 57 (2009)

205. Andreas Nicklisch: Semi-collusive advertising and pricing in experimental duopolies. 2008/25.

204. Andreas Nicklisch: Inequity Aversion, Reciprocity, and Appropriateness in the Ultimatum-Revenge Game. 2008/24.

203. Christoph Engel: The Behaviour of Corporate Actors. A Survey of the Empirical Literature. 2008/23.

202. Emanuel Vahid Towfigh: Komplexität und Normenklarheit - oder: Gesetze sind für Juristen gemacht. 2008/22.

201. Christian Traxler / Andreas Reutter: Apportionment, Fiscal Equalization and Decentralized Tax Enforcement. 2008/21.

200. Christoph Engel, REITs ante portas. Die Anpassung des deutschen Rechts an institutionelle Investoren in den Grundstücksund Mietmärkten. 2008/20.

forthcoming in: Juristenzeitung

199. Christoph Engel, Ernst-Joachim Mestmäcker. 2008/19.

forthcoming in: Stefan Grundmann / Karl Riesenhuber (eds.): Deutschsprachige Zivilrechtslehrer des 20. Jahrhunderts in Berichten ihrer Schüler, Band 2, Berlin (De Gruyter)

198. Andreas Glöckner, „Neurorecht“ ohne Psychologie? Die Rolle verhaltenswissenschaftlicher Betrachtungsebenen bei der Ableitung rechtspolitischer Empfehlungen. 2008/18.

forthcoming in: S. Schleim, T. M. Spranger \& H. Walter (Eds.), Von der Neuroethik zum Neurorecht? Göttingen: Vandenhoeck \& Ruprecht.

197. Ernesto Crivelli/Klaas Staal, Size, Spillovers and Soft Budget Constraints. 2008/17.

196. Niels Petersen, The Principle of Democratic Teleology in International Law. 2008/16.

195. Markus Quirin/Martin Beckenkamp/Julius Kuhl, Giving or Taking: The Role of Dispositional Power Motivation and Positive Affect in Profit Maximization. 2008/15.

194. Andreas Glöckner/Tilmann Betsch/Nicola Schindler, Construction of Probabilistic Inferences by Constraint Satisfaction. 2008/14.

193. Carsten Burhop/Thorsten Lübbers, Cartels, managerial incentives, and productive efficiency in German coal mining, 1881-1913. 2008/13.

192. Andreas Glöckner/Tilmann Betsch, Multiple-Reason Decision Making Based on Automatic Processing. 2008/12. forthcoming in: Journal of Experimental Psychology: Learning, Memory, and Cognition

191. Christian Bayer/Carsten Burhop, Corporate Governance and Incentive Contracts: Historical Evidence from a Legal Reform. 2008/11. 